\title{
Clinical research and the financial markets: opportunities and risks
}

\author{
Peter T Scardino
}

Medicine today has become a complicated business indeed. Expenditures on health care are now responsible for $7-14 \%$ of gross domestic product in developed countries, and in the US exceeded \$1.7 trillion in 2004. Development of new drugs, devices and diagnostic tests attracts over $\$ 100$ billion in investments yearly. Venture capital firms invested over $\$ 6$ billion in biomedical research in $2004-30 \%$ of all venture investments. Understandably, the financial community is intensely interested in medicine, especially the results of clinical trials. Fortunes can hinge on the fate of a particular drug or device.

Financial analysts, brokers and managers, seeking information to enhance their investment decisions, now consult with physicians to an unprecedented degree. Longstanding informal barriers between the financial community and physicians have eroded. Major medical meetings today are often attended by representatives of the financial community, who, at some conferences, outnumber physicians. Consulting firms have networks of physicians under contract to provide insight to brokers and investors. As many as 1 in 10 US physicians reportedly have such relationships, and over 5,000 are estimated to provide regular consultations for varying fees. In academic medical centers, faculty members are frequently contacted with requests for interviews with financial firms; the typical compensation for physicians ranges from $\$ 100$ to $\$ 1000$ an hour.

Physicians tend to be both teachers and healers. We are naturally inclined to explain what we know to those interested in learning. Unfortunately, today, our audience might not always have the same goals we have historically had-the expansion of knowledge for the ultimate benefit of our patients. Those we address in the financial community might have goals that can prove incompatible with optimal patient care. Given the complexity of modern markets, investors can gain an
Those we [physicians] address in the financial community might have goals that can prove incompatible with optimal patient care.

PT Scardino is Editorin-Chief of Nature Clinical Practice Urology.

\section{Competing interests}

The author declared he has no competing interests.

www.nature.com/clinicalpractice doi:10.1038/ncpuro0360 advantage from receiving early information, whether favorable or not, on the safety and efficacy of drugs or devices.

What jeopardy is there in relationships between physicians and financial markets? The opportunity to supplement an income restrained by managed care is an understandable motive, as is the chance to improve the quality of medical solutions that come to market; but the potential risks are serious. A physician privy to the details of a clinical trial might unwittingly violate securities laws by revealing confidential information, even when they have no direct financial relationship with the sponsoring company. These issues are relevant to urologists in private practice, since over $50 \%$ of clinical research is conducted in private offices. In an infamous Florida case, a physician mentioned a severe adverse event in a single patient participating in a trial of an antiobesity drug. As a result, the sponsoring company's stock fell dramatically.

While 'gag rules' that prevent reporting adverse results of trials are to be resisted, revealing results to the investment community before publication is a breach of confidentiality that might have legal consequences. Even physicians not bound by a confidentiality agreement are ethically bound not to disclose unpublished information. As onerous as they have become, it is in the interest of all urologists to understand and comply with the complex regulations that govern modern research and practice. Now, we must also proceed with caution in our interactions with the investment community. Within the past decade a few urologists have been indicted by federal grand juries, removed from leading positions in hospitals and universities, and have lost their reputations, if not their medical licenses, for ethical violations. There are opportunities for enhancing the quality of medical care by appropriate interactions with the financial community, but we must also be fully aware of the rules and the risks. 